\title{
Dyslipidaemia in Nigerian Children and Adolescents with Diabetes Mellitus: Prevalence and Associated Risk Factors
}

\author{
Tamunopriye Caleb Jaja Iroro E. Yarhere \\ Paediatric Endocrinology Unit, Department of Paediatrics and Child Health, University of Port Harcourt Teaching \\ Hospital, Port Harcourt, Nigeria
}

\section{Keywords}

Dyslipidaemia · Diabetes mellitus · Children · Africa

\begin{abstract}
Background: Dyslipidaemia is prevalent in children and adolescents with type 1 diabetes and can worsen the presentation of chronic complications such as nephropathy, retinopathy, and neuropathy. The aim of this study is to determine the frequency of dyslipidaemia in children living with diabetes followed up at a paediatric endocrine clinic in southern Nigeria and to identify associations with demographic and clinical characteristics. Methods: The study is a cross-sectional, descriptive study of 22 children with diabetes followed up in a tertiary health care facility in southern Nigeria. Demographic data were retrieved from case files, and fasting lipid profile and $\mathrm{HbA}_{1 \mathrm{c}}$ levels were determined for all subjects. Lipid abnormalities were defined based on the Expert Panel on Integrated Guidelines for Cardiovascular Health Risk Reduction in Children and Adolescents. Results: Twenty-two subjects aged 7-18 years were studied (mean age: $14.94 \pm 3.59$ years). There were 12 (54.5\%) females. Both genders were comparable regarding age $(p=0.95)$. Mean duration of diabetes was $3.37 \pm 2.38$ years. Prevalence of lipid abnormalities include: hypertriglyceridaemia (86.4\%), hypercholesterolemia (22.7\%), abnormal HDL-C (36.4\%), high
\end{abstract}

LDL-C (13.6\%), and non-HDL-C (22.7\%). Hypercholesterolaemia was significantly higher in females $(p=0.02)$, and prevalence of hypertriglyceridaemia was higher in subjects $\geq 12$ years $(p=0.019)$. There was no statistically significant difference in mean levels of various lipids between males and females. Six (27.3\%) subjects had more than one lipid abnormality. There was no statistically significant association of lipid abnormalities with age, sex, weight category, and $\mathrm{HbA}_{1 \mathrm{c}}$ level. Conclusion: The commonest lipid abnormality was hypertriglyceridaemia. About a quarter of the subjects had more than 1 lipid abnormality. Programs should therefore be targeted at improved control of glycemia and lipid levels to delay and prevent chronic complications.

(c) 2019 The Author(s)

Published by S. Karger AG, Basel

\section{Introduction}

Dyslipidaemia is defined as any abnormality in plasma lipid levels such as decreased high-density lipoprotein (HDL), increased low-density lipoprotein (LDL), triglyceride, or total cholesterol levels $[1,2]$. In youths and adolescents with type 1 diabetes, abnormal lipid levels are a major risk factor for cardiovascular disease later in life and can worsen the presentation of other chronic compli-

\begin{tabular}{ll}
\hline KARGER & $\begin{array}{l}\text { C } 2019 \text { The Author(s) } \\
\text { Published by S. Karger AG, Basel }\end{array}$ \\
E-Mail karger@karger.com & This article is licensed under the Creative Commons Attribution- \\
www.karger.com/ijd & $\begin{array}{l}\text { NonCommercial-NoDerivatives 4.0 International License (CC BY- } \\
\text { NC-ND) (http://www.karger.com/Services/OpenAccessLicense). } \\
\text { Usage and distribution for commercial purposes as well as any dis- } \\
\text { tribution of modified material requires written permission. }\end{array}$
\end{tabular}

Tamunopriye Caleb Jaja

Department of Paediatrics and Child Health

University of Port Harcourt Teaching Hospital

Port Harcourt, Rivers State (Nigeria)

E-Mail Tamunopriyej@yahoo.com 
cations such as nephropathy, retinopathy, and neuropathy with adverse effects on quality of life and life expectancy $[3,4]$.

The effect of lipid abnormalities in diabetes may not be obvious in childhood but may start in childhood and track into adulthood $[1,5]$. The prevalence of lipid abnormalities in children vary with a higher prevalence in children and youths living with diabetes. The frequency of dyslipidaemia in children with type 1 diabetes mellitus (TIDM) varies with prevalence rates as low as $3.8 \%$ and as high as $72.5 \%$ in different studies $[4,6,7]$.

Lipid levels may be affected by several factors, such as glycaemic control, age, duration of diabetes, activity level, diet, and weight category [8]. According to the International Society for Pediatrics and Adolescent Diabetes (ISPAD), screening fasting lipid levels in children and adolescents is recommended from 11 years of age when diabetes is stabilized. However, in children with a family history of hypercholesterolaemia, early cardiovascular disease, or unknown family history, screening should start at 2 years of age [9]. The ISPAD guidelines were inconclusive regarding the other types of lipids but an LDL cholesterol level $>2.6 \mathrm{mmol} / \mathrm{L}(100 \mathrm{mg} / \mathrm{dL})$ was regarded as an indication for intervention to improve metabolic control [9].

In developing countries, reports on dyslipidaemia in diabetes have been mainly in adults. Studies in African children and adolescents living with TIDM are scarce. The pattern of dyslipidaemia in children living with diabetes in sub-Saharan Africa is not widely reported. So the aim of this study is to determine the frequency and pattern of dyslipidaemia in Nigerian children with diabetes followed up at a paediatric endocrine clinic in southern Nigeria and to identify associations with demographic and clinical characteristics.

\section{Methodology}

All subjects $<18$ years treated for diabetes mellitus (DM) with insulin from diagnosis and followed up in the paediatric endocrinology unit from January 1, 2013, till August 2016 were invited to participate in the study. Data on present age, sex, duration of diabetes, admission history, and insulin type and dose used in last month, and history of smoking was obtained from the patient's folder and patients. All patients had $\mathrm{HbA}_{1 \mathrm{c}}$ and fasting lipid profile done at no cost. Subjects 18 years and older, patients not receiving insulin, and those on lipid-lowering drugs were excluded from the study.

Data was collected over 3 months from August to October 2016. Informed consent was obtained from all participants. All parents who gave their consent for the study were instructed concerning fasting by the patient for $12 \mathrm{~h}$ the night before presenting for sample collection. All patients were evaluated and weight and height were measures according to a standard protocol, and BMI and height $z$ scores were determined using WHO Anthroplus Software. BMI $z$ score was classified into weight categories of low weight, normal weight, overweight, and obesity. Weight status was classified as underweight $z$ score of $<-1$, normal weight as $z$ score from -1 to +1 , overweight as +1 to +2 , and obesity as $z$ score $\geq 2$ [10].

Fasting lipid levels were determined using a Randox reagent kit (Liverpool, $\mathrm{UK}$ ) and $\mathrm{HbA}_{1 \mathrm{c}}$ by the BIO-RADin2it ${ }^{\mathrm{TM}}$ analyzer (UK). Lipid abnormalities were defined based on the Expert Panel on Integrated Guidelines for Cardiovascular Health Risk Reduction in Children and Adolescents [11]. Lipid levels were classified into normal and abnormal levels. Abnormal levels were described as total Cholesterol $\geq 200 \mathrm{mg} / \mathrm{dL}$, triglyceride $\geq 150 \mathrm{mg} / \mathrm{dL}$, HDL-C $\leq 45 \mathrm{mg} / \mathrm{dL}$, and LDL-C $\geq 130 \mathrm{mg} / \mathrm{dL}$. Non-HDL-C $\geq 130 \mathrm{mg} / \mathrm{dL}$ was used by adding $30 \mathrm{mg} / \mathrm{dL}$ to ISPAD target LDL of $100 \mathrm{mg} / \mathrm{dL}$ [9]. Dyslipidaemia was diagnosed when one or more lipid values were abnormal [1]. $\mathrm{HbA}_{1 \mathrm{c}}$ was classified as normal if $<7.5 \%$ and abnormal if $\geq 7.5 \%$ [7]. Subjects were also classified into groups $<12$ years and from 12 to 19 years of age. Duration of diabetes was classified into $<5$ years and $\geq 5$ years.

Data was entered into a spreadsheet, and analysis was done using SPSS version 20 (Chicago, IL, USA). Descriptive and comparative analyses were performed using descriptive statistics. Means were compared using independent $t$ test, and the $\chi^{2}$ test and Fisher's exact $t$ test were used to compare proportions.

\section{Results}

Twenty-two subjects were analyzed (age range: 7-18 years; mean age: $14.94 \pm 3.59$ years); their mean duration of diabetes was $3.37 \pm 2.38$ years. There were 12 females $(54.5 \%)$ in the study population, and their mean age of $14.99 \pm 3.70$ years was not significantly different from the mean age of $14.88 \pm 3.64$ for males $(p=0.95)$. There was no history of smoking in any subject studied.

Table 1 shows the demographic and clinical parameters by gender. The mean duration of $\mathrm{DM}, \mathrm{HbA}_{1 c}$, total cholesterol, triglycerides, and non HDL-C were higher in females; however, these findings were not statistically significant. Mean levels of total cholesterol, triglycerides, HDL-C, LDL-C, and non HDL-C of the study population were $154 \pm 48.64,214 \pm 73.00,54.19 \pm 15.65,76.85 \pm$ 37.30 , and $100.38 \pm 45.45$ respectively.

Nineteen (86.4\%) subjects had at least 1 abnormal lipid value while 6 (27.3\%) subjects had 2 or more lipid abnormalities; only 2 (9.0\%) subjects had no lipid abnormality. Tables 2 and 3 show the prevalence of different lipid abnormalities by sex and age group, respectively. The commonest dyslipidaemias were hypertriglyceridaemia in $19(86.4 \%)$ and low HDL-C level in $8(36.4 \%)$. The prevalence of hypercholesterolaemia was significantly
Jaja/Yarhere 
Table 1. Demographic and clinical parameters of the subjects

\begin{tabular}{|c|c|c|c|c|}
\hline Mean parameters & Total & Female & Male & $p$ value \\
\hline Subjects, $n$ & $22(100 \%)$ & $12(54.5 \%)$ & $10(45.5 \%)$ & \\
\hline Age, years & $14.94 \pm 3.6$ & $14.96 \pm 3.7$ & $14.88 \pm 3.6$ & 0.95 \\
\hline Duration of DM, years & $3.37 \pm 2.4$ & $3.85 \pm 2.7$ & $2.75 \pm 1.9$ & 0.28 \\
\hline Height $z$ score & $-0.86 \pm 1.82$ & $-0.40 \pm 1.86$ & $-1.44 \pm 1.66$ & 0.18 \\
\hline BMI $z$ score & $0.00 \pm 1.25$ & $1.00 \pm 1.04$ & $0.00 \pm 1.4$ & \\
\hline Insulin dose, units/kg/day & $0.83 \pm 0.39$ & $0.80 \pm 0.45$ & $0.87 \pm 0.32$ & 0.70 \\
\hline $\mathrm{HbA}_{1 \mathrm{c}}, \%$ & $7.92 \pm 2.12$ & $8.57 \pm 2.18$ & $7.09 \pm 1.80$ & 0.096 \\
\hline Total cholesterol, mg/dL & $154.08 \pm 48.64$ & $159.47 \pm 63.16$ & $147.08 \pm 19.18$ & 0.557 \\
\hline Triglycerides, mg/dL & $212.20 \pm 76.74$ & $233.73 \pm 77.94$ & $184.22 \pm 68.96$ & 0.128 \\
\hline $\mathrm{HDL}-\mathrm{C}, \mathrm{mg} / \mathrm{dL}$ & $54.19 \pm 15.66$ & $53.72 \pm 14.21$ & $54.80 \pm 18.15$ & 0.87 \\
\hline $\mathrm{LDL}-\mathrm{C}, \mathrm{mg} / \mathrm{dL}$ & $76.85 \pm 37.30$ & $77.77 \pm 46.56$ & $75.66 \pm 22.53$ & 0.897 \\
\hline Non-HDL, mg/dL & $100.38 \pm 45.45$ & $106.66 \pm 56.90$ & $92.22 \pm 24.51$ & 0.463 \\
\hline
\end{tabular}

Means \pm SD are shown except for subject number and BMI $z$ score (median).

Table 2. Prevalence of lipid abnormalities by sex

\begin{tabular}{|c|c|c|c|c|}
\hline Lipid type & Total & Female & Male & $\chi^{2}(p$ value $)$ \\
\hline Total cholesterol & & & & $5.39(0.02)$ \\
\hline Normal & $17(77.3 \%)$ & $7(58.3 \%)$ & $10(100 \%)$ & \\
\hline Abnormal & $5(22.7 \%)$ & $5(41.7 \%)$ & $0(0 \%)$ & \\
\hline Triglycerides & & & & $0.206(0.650)$ \\
\hline Normal & $3(13.6 \%)$ & $2(16.7 \%)$ & $1(10 \%)$ & \\
\hline Abnormal & $19(86.4 \%)$ & $10(83.3 \%)$ & $9(90 \%)$ & \\
\hline HDL-C & & & & $1.473(0.225)$ \\
\hline Normal & $14(63.6 \%)$ & $9(75 \%)$ & $5(50 \%)$ & \\
\hline Abnormal & $8(36.4 \%)$ & $3(25 \%)$ & $5(50 \%)$ & \\
\hline LDL-C & & & & $2.895(0.089)^{\mathrm{a}}$ \\
\hline Normal & $19(86.4 \%)$ & $9(75 \%)$ & $10(100 \%)$ & \\
\hline Abnormal & $3(13.6 \%)$ & $3(25)$ & $0(0 \%)$ & \\
\hline Non-HDL-C & & & & $1.691(0.193)$ \\
\hline Normal & $17(77.3 \%)$ & $8(66.7 \%)$ & $9(90 \%)$ & \\
\hline Abnormal & $5(22.7 \%)$ & $4(33.3 \%)$ & $1(10 \%)$ & \\
\hline
\end{tabular}

Numbers of subjects are shown. ${ }^{\text {a }}$ Fisher's exact test.

higher in females $(p=0.02)$. There was no difference in the prevalence of other lipid abnormalities between the sexes. The prevalence of hypertriglyceridaemia in subjects $\geq 12$ years was significantly higher than in subjects $<12$ years $(p=0.019)$. There was no statistically significant difference in the prevalence of other lipid abnormalities according to age group (Table 3).

Table 4 shows the difference in mean variables between subjects with $\geq 2$ and $<2$ dyslipidaemias. There was no statistically significant difference in the mean $\mathrm{HBA}_{1 \mathrm{c}}$, age, BMI percentile, and insulin dose between both age groups. In view of the fact that only 2 subjects did not have dyslipidaemia, subjects who had more than 1 dyslipidaemia and only 1 or none were compared. Table 5 shows the difference in proportion by age, sex, and other characteristics between subjects with $\geq 2$ dyslipidaemias and 1 or no dyslipidaemia. More females, more subjects $\geq 12$ years and more subjects who are overweight and obese had $\geq 2$ dyslipidaemias. But these findings were not statistically significant. 
Table 3. Prevalence of lipid abnormalities by age group

\begin{tabular}{|c|c|c|c|c|}
\hline Lipid type & Total & $<12$ years & $\geq 12$ years & $\chi^{2}(p$ value $)$ \\
\hline Total cholesterol & & & & $0.014(0.905)$ \\
\hline Normal & $17(77.3 \%)$ & $3(75 \%)$ & $14(77.7)$ & \\
\hline Abnormal & $5(22.7 \%)$ & $1(25 \%)$ & $4(22.3 \%)$ & \\
\hline Triglycerides & & & & $5.489(0.019)$ \\
\hline Normal & $3(13.6 \%)$ & $2(50 \%)$ & $1(5.6 \%)$ & \\
\hline Abnormal & $19(86.4 \%)$ & $2(50 \%)$ & $17(94.4 \%)$ & \\
\hline HDL-C & & & & $0.273(0.601)$ \\
\hline Normal & $14(63.6 \%)$ & $3(75 \%)$ & $11(61.1 \%)$ & \\
\hline Abnormal & $8(36.4 \%)$ & $1(25 \%)$ & $7(38.9 \%)$ & \\
\hline LDL-C & & & & $0.772(0.380)^{\mathrm{a}}$ \\
\hline Normal & $19(86.4 \%)$ & $4(100 \%)$ & $15(83.3 \%)$ & \\
\hline Abnormal & $3(13.6 \%)$ & $0(0.0 \%)$ & $3(16.7 \%)$ & \\
\hline Non-HDL-C & & & 1 & $1.436(0.230)^{\mathrm{a}}$ \\
\hline Normal & $17(77.3 \%)$ & $4(100 \%)$ & $13(72.2 \%)$ & \\
\hline Abnormal & $5(22.7 \%)$ & $0(0 \%)$ & $5(27.8 \%)$ & \\
\hline
\end{tabular}

Numbers of subjects are shown. ${ }^{\text {a }}$ Fisher's exact test.

Table 4. Characteristics of subjects based on number of lipid abnormalities

\begin{tabular}{lccc}
\hline Variable & $<2$ lipid abnormality & $\geq 2$ lipid abnormalities & $t$ test $(p$ value $)$ \\
\hline Mean age & $15.15 \pm 3.6$ & $14.78 \pm 3.7$ & $0.238(0.814)$ \\
Mean HbA 1 c & $7.5 \pm 2.3$ & $7.7 \pm 1.9$ & $-1.63(0.872)$ \\
Mean duration of DM & $3.31 \pm 2.4$ & $2.88 \pm 1.6$ & $0.448(0.659)$ \\
Mean BMI percentile & $57.25 \pm 30.8$ & $66.38 \pm 31.9$ & $-0.642(0.529)$ \\
Mean weight & $48.15 \pm 13.7$ & $52.75 \pm 19.6$ & $-0.634(0.534)$ \\
Mean height & $151.46 \pm 15.6$ & $149.88 \pm 15.9$ & $0.225(0.825)$ \\
Mean insulin/kg/day & $0.923 \pm 0.49$ & $0.571 \pm 0.64$ & $1.478(0.157)$ \\
\hline
\end{tabular}

\section{Discussion}

This report reveals a high prevalence of dyslipidaemia in the subjects studied. Eighty-six percent of subjects with TIDM had dyslipidaemia, and this high rate of dyslipidaemia has been reported by other studies in children with TIDM $[7,11,12]$. In their study on dyslipidaemia in Brazilian children with TIDM, Homma et al. [7] reported that $72.5 \%$ of the subjects had dyslipidaemia. Similarly, looking at the significance of lipid abnormalities in children with insulin-dependent DM, Rahma et al. [13] reported a prevalence of $66 \%$.

However, lower prevalence rates of dyslipidaemia have also been reported by other studies $[6,12,14,15]$. The reports by Bulut et al. [14] in children with TIDM and Demirel et al. [15] in Turkish adolescents with TIDM noted dyslipidaemia in 26.2 and $30.3 \%$, respectively. The dif- ference in prevalence recorded by different studies may be due to various reasons, which include differences in target age, diets, treatment regimens, and glycaemic control, and also differences in the reference ranges used by the different studies. In the USA, in a study investigating cardiovascular risk factors in 11,348 children and adolescents aged 2-18 years with TIDM, Redondo et al. [6] reported a prevalence of dyslipidaemia of $3.8 \%$. He attributed the low prevalence to the fact that most of the subjects were young and the low prevalence of obesity in the study subjects.

Looking at the pattern of dyslipidaemia in this study, hypertriglyceridaemia was the commonest dyslipidaemia. The mean triglyceride level in the group was higher than the normal value in the guideline [11]. More than $80 \%$ of the subjects in this study had hypertriglyceridaemia, which is much higher than the values from other studies $[7,13]$. Hypercholesterolaemia has been reported
48

Int J Diabetes Metab 2019;25:45-51 DOI: 10.1159/000499713
Jaja/Yarhere 
Table 5. Relationship between clinical characteristics and dyslipidemia

\begin{tabular}{|c|c|c|c|}
\hline Parameters & $<2$ lipid abnormalities & $\geq 2$ lipid abnormalities & $p$ value \\
\hline Sex & & & 0.264 \\
\hline Male & $9(90 \%)$ & $1(10 \%)$ & \\
\hline Female & $7(58.3 \%)$ & $5(41.7 \%)$ & \\
\hline \multicolumn{4}{|l|}{ Age } \\
\hline$<12$ years & $3(75 \%)$ & $1(25 \%)$ & 0.730 \\
\hline$\geq 12$ years & $13(72.2 \%)$ & $5(41.7 \%)$ & \\
\hline \multicolumn{4}{|l|}{ Duration of diabetes } \\
\hline$<5$ years & $12(70.6 \%)$ & $5(29.4 \%)$ & 0.542 \\
\hline$\geq 5$ years & $4(80.0 \%)$ & $1(20.0 \%)$ & \\
\hline \multicolumn{4}{|l|}{$\mathrm{HbA}_{1 \mathrm{c}}$} \\
\hline$<7.5 \%$ & $6(75 \%)$ & $2(25 \%)$ & 0.666 \\
\hline$\geq 7.5 \%$ & $10(71.4 \%)$ & $4(28.6 \%)$ & \\
\hline \multicolumn{4}{|l|}{ Weight category } \\
\hline Underweight & $1(100 \%)$ & $0(0 \%)$ & $0.769^{\mathrm{a}}$ \\
\hline Normal weight & $11(73.3 \%)$ & $4(26.6 \%)$ & \\
\hline Overweight/obesity & $4(66.7 \%)$ & $2(33.3 \%)$ & \\
\hline Total & $16(100 \%)$ & $6(100 \%)$ & \\
\hline
\end{tabular}

Numbers of subjects are shown. ${ }^{a}$ Fisher's exact test.

as the commonest type of dyslipidaemia in several studies $[13,15,16]$. In the study by Bulut et al. [14], hypercholesterolaemia was the commonest dyslipidaemia while hypertriglyceridaemia was reported in only $12.9 \%$ of subjects. Mona et al. [12] in Egypt reported high LDL-C and low HDL-C as the commonest dyslipidaemias, and hypertriglyceridaemia was reported in $<5 \%$ of subjects. However, in a report of lipid profiles in children with TIDM in Erbil, Alrabaty et al. [17] reported hypertriglyceridaemia as the highest dyslipidaemia. The reasons for the difference in the prevalence of dyslipidaemias may not be very obvious but may be due to differences in the diets, age, glycaemic control, and other associated disease conditions. In this study, although the dietary pattern was not specifically studied, carbohydrates are a dominant part of our diet; suboptimal insulin therapy and poor glycaemic control are also typical and reported in DM children in Africa [18] and may account for the high prevalence of hypertriglyceridaemia compared to other studies. Triglycerides are a flexible source of energy and can be converted to glucose by the liver and readily stored in the adipose tissue usually in the presence of adequate insulin. Recently eaten foods and drinks (i.e., within the last few hours) can lead to increased levels, which underscores the need for fasting before samples are taken. Although the subjects in this study had fasting lipids taken, the immediate explanation for the high triglyceride levels

Dyslipidaemia and Childhood Diabetes Mellitus may be the background poor glycaemic control usually reported in African subjects with diabetes.

Non-HDL-C, a reflection of highly artherogenic apolipoprotein $\mathrm{B}$ and LDL-C, track into adulthood and can usually predict the severity of atherosclerosis in adults $[19,20]$. In this study, 5 (22.7\%) subjects had abnormal levels of these highly atherogenic lipids. In the study amongst Turkish children with TIDM, increased LDL-C was reported in $10.4 \%$ of the subjects, which is in agreement with our study. Higher LDL-C prevalence rates of 20.51 and 44\% were reported in Cairo [12] and Brazil [7], respectively. The higher values reported in the latter is because a lower cutoff $(100 \mathrm{mg} / \mathrm{dL})$ was used for LDL-C compared to the $130 \mathrm{mg} / \mathrm{dL}$ used in this study. According to the ISPAD guidelines on dyslipidaemia, a high LDL-C $(>100 \mathrm{mg} / \mathrm{dL})$ is an indication for intervention to improve metabolic control with diet and increased exercise. Statin should be considered in children if LDL-C does not reduce to $<130 \mathrm{mg}$ after nonmedical intervention [9]. In this study, $13.6 \%$ of the subjects had high LDL levels and therefore will require intervention.

We also observed that the mean values of most lipids were higher in females than males, and more females (41.7\%) had more than 1 dyslipidaemia than males (10\%). The higher prevalence of dyslipidaemia in females has also been observed in other studies [7, 21]. In the study by Homma et al. [7] in Brazilian children with TIDM, a 
higher prevalence of dyslipidaemia (87\%) and a lower prevalence of HDL-C were observed in females. Franca and Alves [21] also reported higher dyslipidaemia prevalence in females $(34.7 \%)$ and males (25.3\%). However, in the study in Turkish children by Bulut et al. [14], prevalence of dyslipidaemia was similar in both males and females: $26.2 \%$ in females versus $26.1 \%$ in males. The reason for the higher tendency to dyslipidaemia in females may have several reasons. Pérez et al. [22], for example, have suggested that in women diabetes has a greater impact on cardiovascular risk than in men. They also noted that women have a higher artherogenic risk than men even when diabetes was well controlled for.

In this study, the mean age was similar for females and males, but females had a higher mean BMI $z$ score and $\mathrm{HbA}_{1 \mathrm{c}}$ level, and mean lipid levels were also higher in females than males. Although not looked at in this report, females of the same age are more likely to be more advanced in puberty than males of that age with a possible effect of estrogen on BMI and glycaemic control [23]. In this study, there was no significant relationship between $\mathrm{HbA}_{1 \mathrm{c}}$, age, duration of diabetes, and weight category and dyslipidaemia. This is similar to observations made by Homma et al. [7] in Brazilian children. However, a relationship has been described between dyslipidaemia and glycaemic control shown by $\mathrm{HbA}_{1 \mathrm{c}}$ in some studies [4, 23, 24]. In our study, a higher prevalence of dyslipidaemia was reported in females who had a higher mean $\mathrm{HbA}_{1 \mathrm{c}}$, but there was no statistically significant difference between subjects who had optimal $\mathrm{HbA}_{1 \mathrm{c}}<7.5 \%$ and subjects with $\mathrm{HbA}_{1 \mathrm{c}} \geq 7.5 \%$. Guy et al. [4] and Teles and Fornés [25] stated that poor glycaemic control was related to higher serum lipid levels. Ladeia et al. [26] also found a significant correlation between glycaemic control and lipid profiles.

Autoimmune comorbidities and micro- and macrovascular complications were not looked at in this study due to the financial burden on the investigators. Further limitations were the poor knowledge and awareness of the nutrient content of local foods, and family knowledge of cardiovascular risk factors were also limitations of the data collected for this study. Most subjects in this study were regarded as TIDM, but no test was performed to confirm the presence of TIDM.

\section{Limitations}

$\mathrm{BMI}$ is a measure of adiposity and correlates with total body fat. Body fat mass distribution was not considered in this study as weight loss was a frequent feature in children and adolescents living with TIDM. Abdominal obesity was also not a significant feature in TIDM.
The ISPAD guideline mentioned only LDL-C in its guideline hence the use of a more comprehensive panel.

Diet was not looked at in this study because details on caloric and nutrient contents of most of our diets are not known and preparation methods vary, which could affect nutrient content.

Waist circumference was not measured in this study; however, even though there was no statistically significant difference regarding weight, the prevalence of dyslipidaemia was higher in overweight/obese than normal weight or underweight subjects.

Most of the subjects enrolled had TIDM. Diagnosis was basically clinical. However, subjects included in this study are only those who have been on only insulin from diagnosis. No subject was on metformin therapy.

Lifestyle and physical activity was not mentioned for patients enrolled in the study as well as blood pressure values and their percentiles.

A prospective and case-control study involving a larger sample will be needed to be able to draw more definite conclusions on dyslipidaemia in children and adolescents living with diabetes in Africa.

\section{Conclusion}

The commonest lipid abnormality was hypertriglyceridaemia. About a quarter of our subjects had more than one lipid abnormality. Programs should therefore aim to improve lipid levels to delay and prevent chronic complications.

\section{Acknowledgment}

We wish to thank the medical officers and laboratory assistants who worked with us in reviewing the patients and doing the laboratory analysis. We appreciate the parents, caregivers, and patients for their consent to participate in this study.

\section{Statement of Ethics}

All parents whose children were studied gave informed consent. Ethical clearance for this study was obtained from the Ethical Committee of the University of the Port Harcourt Teaching Hospital.

\section{Disclosure Statement}

The authors have nothing to disclose.
Jaja/Yarhere 


\section{Funding Sources}

The authors received no funding for this study.

\section{Author Contributions}

Both authors developed and carried out sample collection. Literature review was done by Dr. Tamunopriye Jaja, and both authors did the data analysis and read through the final paper.

\section{References}

1 Maahs DM, Wadwa RP, Bishop F, Daniels SR, Rewers M, Klingensmith GJ. Dyslipidemia in youth with diabetes: to treat or not to treat? J Pediatr. 2008 Oct;153(4):458-65.

2 Schwab KO, Doerfer J, Marg W, Schober E, Holl RW; DPV Science Initiative and the Competence Network Diabetes mellitus. Characterization of 33488 children and adolescents with type 1 diabetes based on the gender-specific increase of cardiovascular risk factors. Pediatr Diabetes. 2010 Aug;11(5): 357-63.

3 Simsek DG, Aycan Z, Özen S, Cetinkaya S, Kara C, Abalı S, et al. Diabetes care, glycemic control, complications, and concomitant autoimmune diseases in children with type 1 diabetes in Turkey: a multicenter study. J Clin Res Pediatr Endocrinol. 2013;5(1):20-6.

4 Guy J, Ogden L, Wadwa RP, Hamman RF, Mayer-Davies EJ, Liese AD, et al. Lipid and lipoprotein profiles in youth with and without type 1 diabetes: the SEARCH for Diabetes in Youth case-control study. Diabetes Care. 2009 Mar;32(3):416-20.

5 Feitosa AC, Feitosa-Filho GS, Freitas FR, Wajchenberg BL, Maranhão RC. Lipoprotein metabolism in patients with type 1 diabetes under intensive insulin treatment. Lipids Health Dis. 2013 Feb;12:15.

6 Redondo MJ, Foster NC, Libman IM, Mehta SN, Hathway JM, Bethin KE, et al. Prevalence of cardiovascular risk factors in youth with type 1 diabetes and elevated body mass index. Acta Diabetol. 2016 Apr;53(2):271-7.

7 Homma TK, Endo CM, Saruhashi T, Mori AP, Noronha RM, Monte O, et al. Dyslipidemia in young patients with type 1 diabetes mellitus. Arch Endocrinol Metab. 2015 Jun; 59(3):215-9.

8 Marcovecchio ML, Tossavainen $\mathrm{PH}$, Heywood JJ, Dalton RN, Dunger DB. An independent effect of parental lipids on the offspring lipid levels in a cohort of adolescents with type 1 diabetes. Pediatr Diabetes. 2012 Sep;13(6): 463-9.
9 Donaghue KC, Wadwa RP, Dimeglio LA, Wong TY, Chiarelli F, Marcovecchio ML, et al; International Society for Pediatric and Adolescent Diabetes. ISPAD Clinical Practice Consensus Guidelines 2014. Microvascular and macrovascular complications in children and adolescents. Pediatr Diabetes. 2014 Sep; 15 Suppl 20:257-69.

10 World Health Organization. WHO child growth standards: length/height-for-age, weight-for-age, weight-for-length, weightfor-height and body mass index-for-age: methods and development. Geneva: WHO; 2016 [accessed 2014 Feb 4]. Available from: http://www.who.int/iris/handle/10665/ 43413.

11 Expert Panel on Integrated Guidelines for Cardiovascular Health and Risk Reduction in Children and Adolescents; National Heart, Lung, and Blood Institute. Expert panel on integrated guidelines for cardiovascular health and risk reduction in children and adolescents: summary report. Pediatrics. 2011 Dec; 128 Suppl 5:S213-56.

12 Mona HM, Sahar SA, Hend SM, Nanees AW. Dyslipidemia in type 1 diabetes mellitus. Relation to diabetes duration, glycemic control, body habitus, dietary intake and other epidemiological risk factors. Egyptian Pediatric Assoc Gazette. 2015;63(2):63-8.

13 Rahma S, Rashid JA, Farage AH. The significance of lipid abnormalities in children with insulin dependent DM. Iraqi Postgrad Med J. 2006;5:289-94.

14 Bulut T, Demirel F, Metin A. The prevalence of dyslipidemia and associated factors in children and adolescents with type 1 diabetes. J Pediatr Endocrinol Metab. 2017 Feb;30(2): 181-7.

15 Demirel F, Tepe D, Kara O, Esen I. Microvascular complications in adolescents with type 1 diabetes mellitus. J Clin Res Pediatr Endocrinol. 2013 Sep;5(3):145-9.

16 Polkowska A, Głowińska-Olszewska B, Tobiaszewska M, Bossowski A. [Risk factors for cardiovascular disease in children with type 1 diabetes in 2000-2010 in Podlasie Province]. Pediatr Endocrinol Diabetes Metab. 2015; 20(2):47-54. Polish.
17 Alrabaty AA, Alnakshabandi AA, Yahya NB. The lipid profile in children with type 1 diabetes mellitus in Erbil governorate. Iraqi Postgrad Med J. 2009;8:344-9.

18 Ngwiri T, Were F, Predieri B, Ngugi P, Iughetti L. Glycemic control in Kenyan children and adolescents living with Type 1 Diabetes Mellitus. Int J Endocrinol. 2015;2015:761759.

19 Kim SH, Jung IA, Jeon YJ, Cho WK, Cho KS, Park SH, et al. Serum lipid profiles and glycemic control in adolescents and young adults with type 1 diabetes mellitus. Ann Pediatr Endocrinol Metab. 2014 Dec;19(4):191-6.

20 Bamba V. Update on screening, etiology, and treatment of dyslipidemia in children. J Clin Endocrinol Metab. 2014 Sep;99(9):3093-102.

21 Franca E, Alves JG. Dyslipidemia entre criacas e adolescents de Pernambuco. Arq Bras Cardiol. 2006;87(6):722-7.

22 Pérez A, Wägner AM, Carreras G, Giménez G, Sánchez-Quesada JL, Rigla M, et al. Prevalence and phenotypic distribution of dyslipidemia in type 1 diabetes mellitus: effect of glycemic control. Arch Intern Med. 2000 Oct; 160(18):2756-62.

23 Chowdhury S. Puberty and type 1 diabetes. Indian J Endocrinol Metab. 2015 Apr;19(7 Suppl 1):S51-4.

24 Gluffrida FM, Guedes AD, Rocco ER, Mory AB, Dualib P, Matos OS, et al; Brazillian Type 1 diabetes study group(BrazDiabi SG). Heterogenous behavior of lipids according to $\mathrm{HbAlc}$ levels undermines the plausibility of metabolic syndrome in type 1 diabetes: data from nationwide multicenter survey. Cardiovasc Diabetol. 2012;11:156.

25 Teles SA, Fornés NS. [Relationship between anthropometric and biochemical profiles in children and adolescents with type 1 diabetes]. Rev Paul Pediatr. 2012;30:65-71. Spanish.

26 Ladeia AM, Adan L, Couto-Silva AC, Hiltner A, Guimarães AC. Lipid profile correlates with glycemic control in young patients with type 1 diabetes mellitus. Prev Cardiol. 2006; $9(2): 82-8$. 